\title{
Association between airflow limitation severity and reduced bone mineral density in Japanese men
}

This article was published in the following Dove Press journal:

International Journal of Chronic Obstructive Pulmonary Disease

\author{
Kazuhiko Watanabe' \\ Ayumi Onoue' \\ Kenichi Kubota ${ }^{2}$ \\ Noritaka Higashi ${ }^{2}$ \\ Toshinari Hayashi ${ }^{3}$ \\ Tohru Tsuda (1D ${ }^{4}$ \\ Hisamitsu Omori $\mathbb{D}^{\prime}$ \\ 'Department of Biomedical Laboratory \\ Sciences, Faculty of Life Sciences, \\ Kumamoto University, Kumamoto 862- \\ 0976, Japan; ${ }^{2}$ Department of Respiratory \\ Medicine, Japanese Red Cross Kumamoto \\ Health Care, Kumamoto 86I-8528, Japan; \\ ${ }^{3}$ Tokorozawa Respiratory Clinic, \\ Tokorozawa, Saitama, Japan; ${ }^{4}$ Kirigaoka \\ Tsuda Hospital, Kitakyusyu, Fukuoka, \\ Japan
}

Correspondence: Hisamitsu Omori Department of Biomedical Laboratory Sciences, Faculty of Life Sciences, Kumamoto University, 4-24-I Kuhonji, Chuo-ku Kumamoto, Kumamoto 862-0976, Japan

Tel +8I 963735462

Fax +8I 963735462

Email omorih@gpo.kumamoto-u.ac.jp
Introduction: This study aimed to assess the association between airflow limitation (AL) severity and reduced bone mineral density (BMD) in Japanese men.

Subjects and methods: This cross-sectional study included 290 subjects aged over 40 years (mean age 72.0, SD 11.6), who underwent a comprehensive health examination, including spirometry and measurement of BMD at the left femoral neck using dual-energy X-ray absorptiometry (DXA), between 2016 and 2017 at Japanese Red Cross Kumamoto Health Care Center. $\mathrm{AL}$ was defined as forced expiratory volume in one second $\left(\mathrm{FEV}_{1}\right)$ /forced vital capacity (FVC) of $<0.7$. Reversibility tests were not performed in this study. The criteria used for the AL staging were developed according to the Global Initiative for Chronic Obstructive Pulmonary Disease (GOLD) guidelines. The subjects were divided into the following three groups: a control group (normal pulmonary function), GOLD Stage I group (mild AL), and GOLD Stage II-IV group (moderate-to-very severe AL). BMD was classified based on the young adult mean (YAM) as normal $(88.6 \% \leqq$ YAM $[-1 \mathrm{SD} \leqq])$, osteopenia $(70 \%<$ YAM $<88.6 \%[<-1$ SD and $>-2.5$ $\mathrm{SD}]$ ), or osteoporosis (YAM $\leqq 70 \%[\leqq-2.5 \mathrm{SD}]$ ). Reduced BMD was defined as osteopenia, osteoporosis, or medication used for osteoporosis. Logistic regression analysis was used to assess the association between AL severity and the reduced BMD.

Results: The prevalence of reduced BMD in subjects with moderate-to-severe AL (76.2\%) was significantly higher than in those without $\mathrm{AL}(47.9 \%)(p=0.030)$. In logistic regression models adjusted for age, body mass index, pack-years, physical activity, and alcohol drinking, the risk of reduced BMD (odds ratio: 3.87; 95\% confidence interval: 1.20-12.49; $p=0.024$ ) was significantly higher in subjects with moderate-to-severe AL than in those with normal pulmonary function.

Conclusion: Present results suggest that reduced BMD is associated with AL severity in Japanese men.

Keywords: chronic obstructive pulmonary disease, comorbidity, bone mineral density, osteoporosis, airflow limitation, pulmonary function

\section{Introduction}

Chronic obstructive pulmonary disease (COPD) is a common, preventable, and treatable disease that is characterized by persistent respiratory symptoms and restricted airflow due to airway and/or alveolar abnormalities. ${ }^{1}, 2$ The primary cause of COPD is tobacco exposure through active smoking or second-hand smoke. Other risk factors include exposure to indoor and outdoor air pollution, occupational dust, and fumes. ${ }^{3}$ The World Health Organization reported that COPD is the third leading cause of death globally, causing three million deaths in $2016 .{ }^{4}$ The incidence of COPD is likely to increase in the coming years due to an increase in smoking habits and an aging population in many countries. ${ }^{3}$ COPD is a major cause of chronic morbidity and 
mortality throughout the world; many people suffer from this disease for years and die prematurely from the disease or its complications. COPD is regarded as a systemic disease because it can cause systemic effects and induce comorbidities. $^{5}$ COPD often coexists with other diseases (comorbidities) that may have a significant impact on prognosis. $^{2}$ The comorbidities include nutritional disorders, skeletal muscle dysfunction, cardiovascular disease, osteoporosis, anxiety/depression, metabolic syndrome/diabetes, gastroesophageal reflux disease (GERD), sleep apnea syndrome (SAS) and lung cancer. ${ }^{2,5}$ The major systemic consequences/comorbidities are deconditioning, exercise intolerance, skeletal muscle dysfunction, cardiovascular disease, osteoporosis, metabolic impact, anxiety/depression, diabetes, and hypertension. ${ }^{6,7}$ These comorbidities are associated with hospitalization, burden on the healthcare system and mortality in patients. ${ }^{1,2,6,8-10}$ Therefore, effective treatment for comorbidities plays a central role in COPD management. $^{11}$

Osteoporosis, which is often under-diagnosed, is a major and common comorbidity in COPD. ${ }^{1}$ It is associated with poor health and prognosis if left untreated. ${ }^{1,2,12,13}$ Osteoporosis is common in COPD and should be a major concern in the diagnostic and therapeutic approach to COPD patients, who may benefit from osteoporosis assessment and therapy. ${ }^{13}$ Osteoporosis is a silent disease, unless complicated by fractures. Patients with osteoporosis are at an increased risk of fracture, particularly fragility fractures. ${ }^{14}$ Recent studies have demonstrated that COPD is related to low bone mineral density (BMD) and increased fractures of the vertebra and hip. ${ }^{15-20}$ In addition, patients with COPD have a higher risk of death following a hip fracture. ${ }^{21,22}$ Furthermore, several previous studies have shown that reduced respiratory function is related to low BMD and increased fracture risk. ${ }^{23-25}$

In Japan, osteoporosis is present in up to $35 \%$ of the COPD patients, but most of these patients are not evaluated or treated for osteoporosis. ${ }^{5}$ There are few studies examining the association between BMD and the severity of airflow limitation (AL) in Japan. Therefore, the aim of present study was to assess the association between $\mathrm{AL}$ and BMD of the femoral neck among Japanese men.

\section{Subjects and methods Subject selection}

Figure 1 shows the criteria for selecting the subjects with either AL or a normal pulmonary function. A total of
27,234 Japanese men visited the Japanese Red Cross Kumamoto Health Care Center for medical health checkups between April 2016 and September 2017. Of these, 395 patients underwent a health screening examination that included spirometry, as previously described, ${ }^{26-31}$ and an optional one-time measurement of BMD.

The screening examination included questionnaires, a physical examination, and blood sampling. The questionnaires were conducted by a trained public health nurse to obtain data on medical history, including the use of medications, and smoking habits. ${ }^{30}$ The never smokers consisted of those who denied any past or current smoking. The former smokers were those who reported smoking cessation prior to the examination. The current smokers were those who reported smoking at least one cigarette a day. The number of cigarette pack-years was calculated by multiplying the number of years of smoking by the average number of cigarettes smoked per day and dividing it by 20 . All the participants were evaluated by a physician. The subjects under 40 years old $(n=6)$ were excluded. The subjects with forced expiratory volume in one second/ forced vital capacity $\left(\mathrm{FEV}_{1} / \mathrm{FVC}\right) \geqq 70 \%$ and $\%$ $\mathrm{FEV}_{1}<80 \%$ predicted $(\mathrm{n}=31)$ were excluded from this study. The subjects with self-reported asthma $(n=20)$, tuberculosis $(n=12)$, other respiratory diseases $(n=10)$, and thyroid disease $(n=26)$ were also excluded. In this study, none of the subjects were diagnosed with COPD with acute exacerbation or lung cancer or were under corticosteroid medication. Data from a total of $290 \mathrm{sub}-$ jects (mean age 72.0, SD 11.6) were included in the final analyses (Figure 1, Table 1). Subjects who gave written informed consent were included in this study. This study was conducted in accordance with the Declaration of Helsinki and the Ethical Guidelines for Epidemiological Research (partially revised on December 1, 2008 by the Ministry of Education, Culture, Sports, Science and Technology and the Ministry of Health, Labour and Welfare). The research protocol was approved by the Human Ethics Committee of Kumamoto University (Number 84) and the Japanese Red Cross Kumamoto Health Care Center.

\section{Pulmonary function tests}

Spirometry was performed using an electronic spirometer (DISCOM-21 FX: CHEST MI, Tokyo, Japan), as previously described. ${ }^{26-31}$ The use of equipment and quality criteria were compliant with international recommendations. ${ }^{32}$ Pulmonary function tests were performed in accordance 


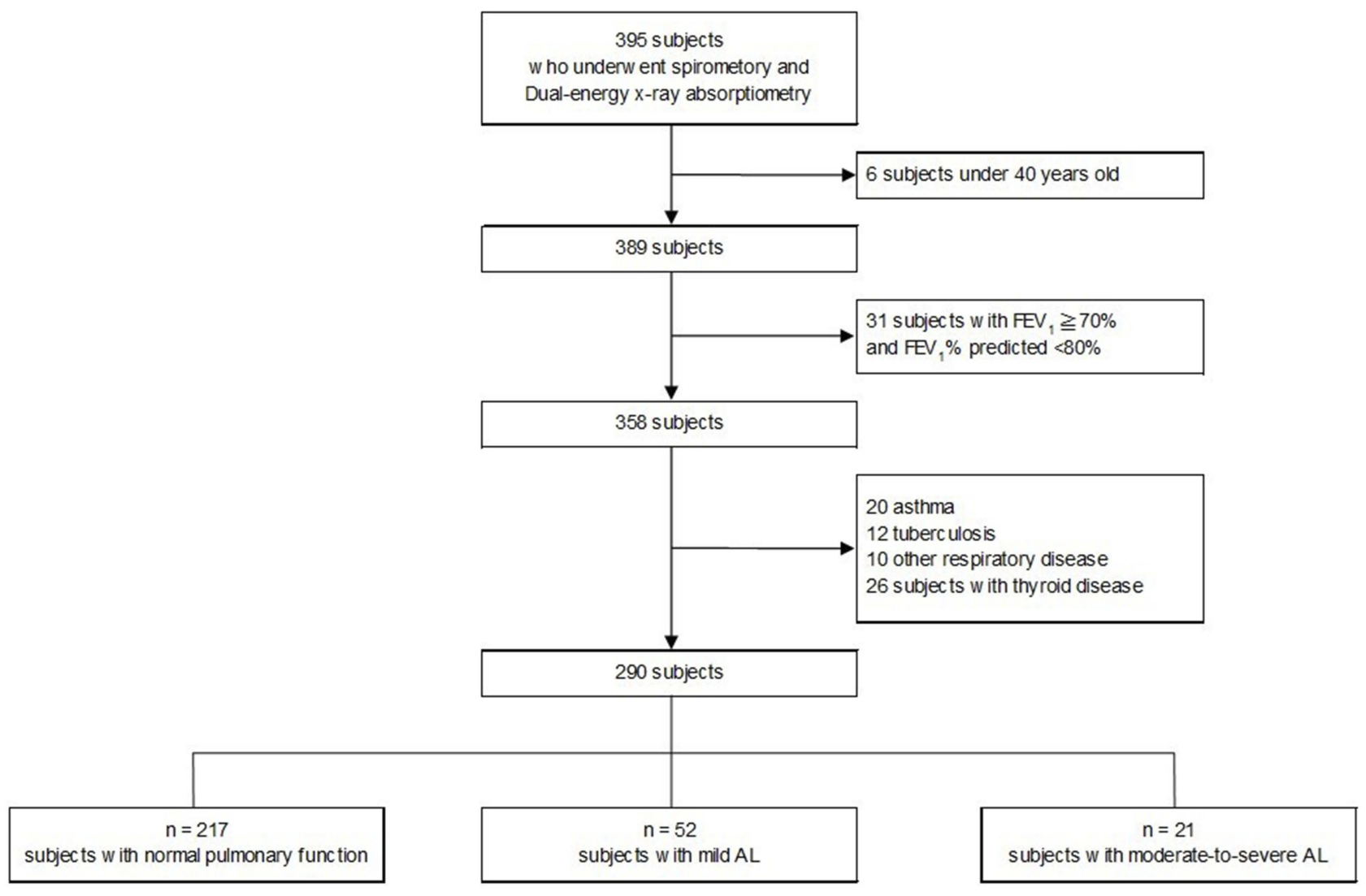

Figure I Flow chart for selecting the subjects with $\mathrm{AL}$ or normal pulmonary function. AL air flow limitation, FEV , forced expiratory in Is.

with the American Thoracic Society and European Respiratory Society guidelines. ${ }^{32}$ Reversibility tests were not performed in this study, and the classifications were based on the pre-bronchodilator levels. AL was defined as $\mathrm{FEV}_{1} / \mathrm{FVC}$ ratio of $<70 \%$, according to the Global Initiative for Chronic Obstructive Pulmonary Disease (GOLD) guidelines. ${ }^{1}$

Predicted values were calculated by the equation published by the Japanese Respiratory Society (JRS). ${ }^{33}$ Predicted values of $\mathrm{FEV}_{1}(\mathrm{~mL})$ for men $=0.036 \times$ Height (cm) $-0.028 \times$ Age -1.178 . The criteria used for AL staging were also developed according to the GOLD guidelines, as follows: Stage I (mild $\mathrm{AL}$ ): $\mathrm{FEV}_{1} / \mathrm{FVC}$ $<70 \%$ and $\% \mathrm{FEV}_{1} \geqq 80 \%$; Stage II (moderate $\mathrm{AL}$ ): $\mathrm{FEV}_{1} / \mathrm{FVC}<70 \%$ and $50 \% \leqq \% \mathrm{FEV}_{1}<80 \%$; Stage III (severe $\mathrm{AL}$ ): $\quad \mathrm{FEV}_{1} / \mathrm{FVC}<70 \%$ and $30 \% \leqq \%$ $\mathrm{FEV}_{1}<50 \%$; and Stage IV (very severe $\mathrm{AL}$ ): $\mathrm{FEV}_{1} / \mathrm{FVC}$ $<70 \%$ and $\% \mathrm{FEV}_{1}<30 \%$.

The subjects were divided into the following three groups as previously described: ${ }^{28,30}$ a control group (normal pulmonary function), GOLD Stage I group (mild AL), and GOLD Stage II-IV group (moderate-to-very severe $\mathrm{AL})$. The subjects with a normal pulmonary function were defined as having $\mathrm{FEV}_{1} / \mathrm{FVC} \geqq 70 \%$ and $\mathrm{FEV}_{1} \geqq$ $80 \%$ of predicted values.

\section{Bone mineral density}

Dual-energy X-ray absorptiometry (DXA) (Discovery Ci: Hologic Inc., USA) was used to measure the left femoral neck BMD (except in subjects with left hip prosthesis or hip fracture). Diagnosis of osteopenia and osteoporosis were conducted according to the WHO criteria. ${ }^{34}$ Based on the young adult mean (YAM), the following criteria were used: normal: $88.6 \% \leqq$ YAM $(-1 \mathrm{SD} \leqq)$, osteopenia: $70 \%<$ YAM $<88.6 \%(<-1 \mathrm{SD}$ and $>-2.5 \mathrm{SD})$, and osteoporosis: YAM $\leqq 70 \%$ ( $\leqq-2.5 \mathrm{SD}$ ). Reduced BMD was defined as osteopenia, osteoporosis, or medication used for osteoporosis.

\section{Physical examination and blood measurements}

Patients were at rest before fasting blood samples were obtained to measure serum levels of routine medical checkups markers, including fasting glucose, triglycerides, highdensity lipoprotein cholesterol (HDL-C), low-density 
Table I The characteristics of the subjects based on pulmonary function

\begin{tabular}{|c|c|c|c|c|}
\hline & $\begin{array}{l}\text { Normal pulmonary function } \\
n=217\end{array}$ & $\begin{array}{l}\text { Mild AL } \\
n=52\end{array}$ & Moderate-to-severe AL $n=21$ & $p$-value \\
\hline Age, $y r$ & $70.0(12.0)$ & $78.1(7.5)^{* *}$ & $77.3(7.3)^{*}$ & $<0.001$ \\
\hline Height, cm & $164.9(5.9)$ & $163.3(6.9)$ & $164.2(5.9)$ & 0.259 \\
\hline Weight, kg & $62.5(9.8)$ & $60.4(8.0)$ & $59.6(7.3)$ & 0.174 \\
\hline Abdominal circumference, $\mathrm{cm}$ & $84.3(8.5)$ & $84.1(6.5)$ & $84.2(7.7)$ & 0.988 \\
\hline $\mathrm{BMI}, \mathrm{kg} / \mathrm{m}^{2}$ & $23.0(3.1)$ & $22.6(2.2)$ & $22.1(2.5)$ & 0.375 \\
\hline Systolic blood presure, $\mathrm{mmHg}$ & $128.7(16.0)$ & $131.0(15.2)$ & $127.5(\mid 4.1)$ & 0.579 \\
\hline Diastolic blood pressure, $\mathrm{mmHg}$ & $73.7(10.2)$ & $73.5(9.2)$ & $73.2(9.9)$ & 0.965 \\
\hline $\begin{array}{l}\text { Smoking status, } \mathrm{n}(\%) \\
\text { Never smokers } \\
\text { Former smokers } \\
\text { Current smokers } \\
\text { Pack-years }\end{array}$ & $\begin{array}{l}85(39.2) \\
120(55.3) \\
12(5.5) \\
13.0(16.7)\end{array}$ & $\begin{array}{l}16(30.8) \\
30(57.7) \\
6(11.5) \\
22.5(25.1)^{*}\end{array}$ & $\begin{array}{l}2(9.5) \\
16(76.2) \\
3(14.3) \\
37.0(26.2)^{* * \#}\end{array}$ & $\begin{array}{l}0.036 \\
<0.001\end{array}$ \\
\hline $\begin{array}{l}\text { Physical activity, n (\%) } \\
\text { Regular } \\
\text { Inactive }\end{array}$ & $\begin{array}{l}72(33.2) \\
145(66.8)\end{array}$ & $\begin{array}{l}22(42.3) \\
30(57.7)\end{array}$ & $\begin{array}{l}7(33.3) \\
14(66.7)\end{array}$ & 0.458 \\
\hline $\begin{array}{l}\text { Alcohol drinking, n (\%) } \\
\text { Non } \\
\text { I-6 days per week } \\
\text { Daily }\end{array}$ & $\begin{array}{l}64(29.5) \\
106(48.8) \\
47(21.7)\end{array}$ & $\begin{array}{l}19(36.5) \\
18(34.6) \\
15(28.9)\end{array}$ & $\begin{array}{l}8(38.1) \\
10(47.6) \\
3(14.3)\end{array}$ & 0.346 \\
\hline $\begin{array}{l}\text { Pulmonary function } \\
\text { FVC, mL } \\
\mathrm{FEV}, \mathrm{mL} \\
\mathrm{FEV} / \mathrm{FVC}, \% \\
\mathrm{FEV}_{1} \% \text { predicted, } \%\end{array}$ & $\begin{array}{l}3,591.5(641.9) \\
2,758.0(517.4) \\
76.9(5.6) \\
98.9(11.1)\end{array}$ & $\begin{array}{l}3,581.9(657.6) \\
2,326.2(414.8)^{* *} \\
65.1(3.5)^{* *} \\
92.8(9.5)^{* *}\end{array}$ & $\begin{array}{l}2,985.2(469.5)^{* * \ldots \#} \\
1,774.3(330.6)^{* * \ldots \#} \\
60.1(9.2)^{* * \ldots \#} \\
69.2(9.3)^{* * \ldots \#}\end{array}$ & $\begin{array}{l}<0.001 \\
<0.001 \\
<0.001 \\
<0.001\end{array}$ \\
\hline $\begin{array}{l}\text { Laboratory data } \\
\text { Fasting glucose, } \mathrm{mg} / \mathrm{dL}(\mathrm{n}=244) \\
\text { Triglycerides, } \mathrm{mg} / \mathrm{dL} \\
\text { (interquartile range) } \\
\mathrm{HDL} \text { cholesterol, } \mathrm{mg} / \mathrm{dL} \\
\mathrm{LDL} \text { cholesterol, } \mathrm{mg} / \mathrm{dL} \\
\text { White blood cell count, / } \mu \mathrm{L} \\
\text { hsCRP } \\
\text { (interquartile range) }\end{array}$ & $\begin{array}{l}104.7(15.5) \\
81.0(64.0-121.0) \\
63.8(15.1) \\
119.1(28.6) \\
5,100.0(1,398.8) \\
0.06(0.03-0.12)\end{array}$ & $\begin{array}{l}101.8(11.8) \\
86.5(70.5-115.5) \\
64.3(15.7) \\
123.2(25.1) \\
5,223.1(1,595.5) \\
0.07(0.05-0.13)\end{array}$ & $\begin{array}{l}101.2(10.2) \\
100.0(64.0-125.0) \\
62.2(15.5) \\
111.2(30.9) \\
5,609.5(1,474.4) \\
0.08(0.05-0.16)^{*}\end{array}$ & $\begin{array}{l}0.342 \\
0.531 \\
0.873 \\
0.259 \\
0.285 \\
<0.05\end{array}$ \\
\hline
\end{tabular}

Notes: Data are expressed as means (standard deviation), median (interquartile range), or as number (n) (percentage) Airflow limitation (AL) was defined as $\mathrm{FEV} / \mathrm{FVC}<$ 0.7. Pack years $=$ (number of cigareetes smoked per day $x$ number of year smokedy)/20. BMI body mass index, FVC forced vital capacity, FEV forced expiratory volume in one second, HDL high-density lipoprotein, LDL low-density lipoprotein, hsCRP hypersensitivity C-reactive protein. ${ }^{*} \mathrm{p}<0.05$, ${ }^{* *} \mathrm{p}<0.0 \mathrm{l}$ compared with normal pulmonary function. ${ }^{\#} p<0.05,{ }^{\#} p<0.01$ compared with mild airflow limitation.

lipoprotein cholesterol (LDL-C), white blood cell count, and high sensitivity C-creative protein (hsCRP). Subjects' abdominal circumferences were measured at the end of exhalation in a standing position. Systolic blood pressure (SBP) and diastolic blood pressure (DBP) were measured by trained nurses using an automatic digital sphygmomanometer (HEM-904; OMRON, Kyoto, Japan) placed on the upper arm at the height of the heart with the patient in a sitting position after $5 \mathrm{~min}$ of rest. The average of two measurements was used for analysis. Body mass index (BMI) was calculated as weight $(\mathrm{kg})$ divided by the square of the height $\left(\mathrm{m}^{2}\right)$. Physical activity was divided into two categories; "regular physical activity" was defined as physical activity performed regularly at least once per week throughout the year, and 
"physical inactivity" was defined as engaging in irregular physical activity or engaging in no form of physical activity at all. Subjects were classified based on alcohol intake as "non-drinkers," "consuming alcohol for 1-6 days per week," and "daily drinkers."

\section{Statistical analyses}

Data were presented as number of cases, mean \pm standard deviation (SD), or median with interquartile range. The normality of distribution was assessed by Shapiro-Wilk test. One-way analysis of variance and Kruskal-Wallis test were used to assess the difference in characteristics among normal pulmonary function, mild AL, and moderate-to-very severe AL. A multivariate logistic regression model adjusted for age, BMI, pack-years, physical activity, and alcohol drinking was used to assess the association between $\mathrm{AL}$ and reduced BMD according to pulmonary function. $p<0.05$ was considered significant. All statistical analyses were conducted using IBM SPSS Statistics 22.0 software. There were no missing data in the present study.

\section{Results}

\section{Study population characteristics}

Table 1 shows the baseline characteristics of the study subjects based on their pulmonary function status. Two hundred and ninety subjects were included in the final analysis. Among the 290 subjects, 217 (74.8\%) had normal pulmonary function, 52 (17.9\%) had mild AL, and 21 (7.2\%) had moderate-to-severe AL according to the GOLD stages (Figure 1). Among 21 subjects with moderate-to-severe AL, most of the subjects were moderate $(n=20,95.2 \%)$ compared to severe $(n=1$, $4.8 \%$ ). No subject with very severe AL was identified in the present study. Significant differences in the pulmonary function status were found in relation to age, pack-years, and hsCRP. Age and pack-years were higher in subjects with mild and moderate-to-severe AL than in those with normal pulmonary function. Mean hsCRP was higher in subjects with moderate-to-severe AL than in those with normal pulmonary function. There was no difference in the mean white blood cell count among the three groups.

\section{Prevalence of reduced bone mineral density}

Table 2 shows the prevalence of reduced BMD in subjects with normal pulmonary function, mild AL, and moderateto-severe AL. In subjects with normal pulmonary function, mild AL, and moderate-to-severe AL, the prevalence of reduced BMD was 47.9\% $(n=104), 57.7 \%(n=30)$, and $76.2 \%(n=16)$, respectively. In the present study, the prevalence of osteopenia in subjects with normal pulmonary function, mild AL, and moderate-to-severe AL was 39.6\% $(n=86), 44.2 \%(n=23)$ and $71.4 \%(n=15)$, respectively. The prevalence of osteoporosis in subjects with normal pulmonary function, mild $\mathrm{AL}$, and moderate-to-severe $\mathrm{AL}$ was $3.7 \%(n=8), 1.4 \%(n=1)$, and $0 \%(n=0)$, respectively. Furthermore, the prevalence of medication used for osteoporosis in subjects with normal pulmonary function, mild $\mathrm{AL}$, and moderate-to-severe AL was 4.6\% $(\mathrm{n}=10), 11.5 \%$ $(n=6)$ and $4.8 \%(n=1)$, respectively.

\section{Odds ratio for the prevalence of reduced bone mineral density}

Table 3 shows the association between AL and reduced BMD according to pulmonary function. Using the logistic regression models adjusted for age, BMI, pack-years, physical activity, and alcohol drinking, the risk of reduced BMD [odds ratio: 3.87 ; 95\% confidence interval: $1.20-$ 12.49] was significantly higher in subjects with moderateto-severe AL than in those with normal pulmonary function.

Table 2 Prevalence of reduced bone mineral density according to AL severity

\begin{tabular}{|c|c|c|c|c|}
\hline & \multicolumn{4}{|c|}{ AL severity } \\
\hline & Normal & Mild & Moderate-to-severe & $p$-value \\
\hline Number of participants & 217 & 52 & 21 & \\
\hline Reduced bone mineral density & $104(47.9)$ & $30(57.7)$ & $16(76.2)$ & 0.030 \\
\hline Osteopenia & $86(39.6)$ & $23(44.2)$ & $15(7 \mid .4)$ & \\
\hline Osteoporosis & $8(3.7)$ & I (I.4) & $0(0)$ & \\
\hline Medication used for osteoporosis & $10(4.6)$ & $6(11.5)$ & I (4.8) & \\
\hline
\end{tabular}

Notes: Data are expressed as number ( $\mathrm{n}$ ) (percentage). Airflow limitation (AL) was defined as FEV $/ \mathrm{FVC}<0.7$. Reduced bone mineral density was defined as osteopenia, osteoporosis, or medication used for osteoporosis. 
Table 3 Association between $\mathrm{AL}$ and reduced bone mineral density according to pulmonary function

\begin{tabular}{|l|l|l|l|l|l|}
\hline \multirow{2}{*}{} & \multicolumn{4}{|c|}{ AL } \\
\cline { 2 - 7 } & Normal pulmonary function, $\mathbf{n = 2 1 7}$ & Mild AL, $\mathbf{n = 5 2}$ & $\mathbf{p}$-value & Moderate-to-severe AL, $\mathbf{n = 2 ~ I ~}$ & $\mathbf{p}$-value \\
\hline Crude & Reference & $1.48(0.80-2.73)$ & 0.207 & $3.48(1.23-9.83)$ & 0.019 \\
Adjusted & Reference & $1.38(0.69-2.78)$ & 0.366 & $3.87(1.20-12.49)$ & 0.024 \\
\hline
\end{tabular}

Notes: Adjusted for age, body mass index, pack-years, physical activity, and alcohol drinking Airflow limitation (AL) was defined as FEV $/$ FVC < 0.7 .

\section{Discussion}

There are few studies describing a link between the severity of $\mathrm{AL}$ and reduced BMD, especially among subjects undergoing medical health checkups. This study demonstrates that moderate-to-severe $\mathrm{AL}$, independent of age, BMI, pack-years, physical activity, and alcohol drinking, is associated with reduced BMD in subjects who undergo a health screening examination.

Several studies have demonstrated an association among pulmonary function, COPD, BMD, and fracture risk in men. Sin et al used DXA to measure BMD of the hip and demonstrated that subjects with airflow obstruction had osteoporosis and the risk of osteoporosis increased in a linear fashion to the severity of airflow obstruction. ${ }^{35}$ Our findings were consistent with the above results. Furthermore, according to a recent study by Herland et al, involving a large sample of community-dwelling, elderly men, AL was associated with reduced BMD of the hip. ${ }^{36}$ Femoral neck fractures often occur in the elderly population. ${ }^{37}$ BMD of the femoral neck, not total hip, was measured using DXA in present study. Therefore, screening for osteoporosis using femoral BMD as an indicator would be useful to prevent hip fracture, which is associated with an increased mortality risk in elderly patients. ${ }^{38,39}$

In our study, the association between AL and reduced BMD seemed to be independent of smoking. Although the association between AL severity and reduced BMD is independent of major known determinants such as age, BMI, pack-years, physical activity, smoking, and alcohol consumption, we could not exclude residual confounders or other unknown factors. Watanabe et al showed a high prevalence of osteoporosis in male Japanese COPD patients and reduced BMD at the lumbar spine (L1-4), femoral neck, and total hip in patients with decreased pulmonary function (GOLD 3-4). ${ }^{25}$ In a similar study by Kjensli et al, BMD of lumbar L2-L4, femoral neck, and total body skeleton decreased with increasing severity of COPD in patients who had not been treated for osteoporosis. ${ }^{40}$ In these studies, however, participants who had been diagnosed with COPD were evaluated. In contrast with our results, Dennison et al, did not find an association between lung function $\left(\mathrm{FEV}_{1}, \mathrm{FVC}, \mathrm{FEV}_{1} /\right.$ FVC) and bone mass after adjustment for body size and other confounders; nevertheless, a weak association was observed between total hip BMD and $\mathrm{FEV}_{1} / \mathrm{FVC}$ ratio in men. ${ }^{41}$ In previous reports, which have shown an association between pulmonary function, COPD, and BMD or fractures. Nuti et al reported a strong association between COPD severity and thoracic fractures on lateral radiographs of men with COPD. ${ }^{19}$ Additionally, a previous study in a large cohort demonstrated that COPD was associated with low BMD and vertebral fracture. ${ }^{42}$ In the present study, BMD of the vertebra was not evaluated; thus fracture risk and reduced BMD of the vertebra were not elucidated. Moreover, presence of fragility fracture was not observed in all subjects.

The detailed mechanisms responsible for reduced BMD in patients with COPD is not clear. However, systemic inflammation represented by elevated CRP is linked to osteoporosis in the general population. ${ }^{43}$ As seen in Table 1, mean hsCRP was significantly higher in subjects with moderate-severe AL than in those with normal pulmonary function. This is consistent with the notion that inflammation plays a role in COPD-associated osteoporosis, and COPD patients with lower BMD have been shown to exhibit higher levels of CRP. ${ }^{44}$ However, despite these observations, the precise role of systemic inflammation in COPD-associated osteoporosis and its contribution to fracture risk remain to be determined.

This study provides an estimate of the prevalence of $\mathrm{AL}$ and reduced BMD among subjects undergoing medical checkups. The prevalence of COPD/emphysema among subjects with AL was only $6.8 \%$ (1.9\% among subjects with mild $\mathrm{AL}$ and $19.0 \%$ among subjects with of the moderate-to-severe AL; data not shown). The remaining had not been diagnosed with any respiratory diseases, suggesting a high degree of underdiagnoses of COPD. Early diagnosis and intervention for COPD and reduced 
BMD can improve the prognosis and reduce the disease burden of COPD on the society.

There are several limitations associated with the present study. First, we were unable to employ reversibility testing because of the absence of high suspicion of disease. Therefore, the subjects with AL could have included those with post-bronchodilator $\mathrm{FEV}_{1} / \mathrm{FVC}$ ratio greater than $70 \%$. Similar to some of previous studies, ${ }^{28,30}$ subjects who were diagnosed with asthma or other respiratory diseases were excluded from this study. These excluded individuals could have had COPD or asthma; thus, we expressed "AL" instead of COPD. As the number of women with AL is low, only men were evaluated in this study, and we were unable to determine the gender-differences in BMD; further research is needed to better understand the gender-difference with regard to this condition. Moreover, limitation of the study is the modest size of the study population. The relatively small sample size for the group of AL meant that comparisons against normal pulmonary function had less statistical power. Recruiting men with severe or very severe AL who underwent medical health checkups and met the study entry criteria proved challenging despite screening large numbers of subjects. Further studies are needed in a large sample that includes subjects with a wider severity range of AL. In addition, serum vitamin D levels were not examined. A previous report suggests that Vitamin D deficiency occurs frequently in COPD and correlates with the severity of the condition. ${ }^{45}$ Furthermore, vitamin D deficiency increases the risk of osteoporosis and osteoporotic fractures. ${ }^{46,47}$ Therefore, the relationship between the serum vitamin D levels, AL and reduced BMD are not clear in the present study. More studies are needed to confirm the association between serum vitamin D levels, AL severity, and BMD.

Because of the cross-sectional design of this study, we could not rule out possibility of reverse causation. Therefore, large-scale prospective studies are needed to further confirm these findings. Despite these limitations, to the best of our knowledge, this is the first study to reveal a relationship between $\mathrm{AL}$ severity and BMD in Japanese men.

\section{Conclusion}

In conclusion, a significant relationship was found between AL severity and reduced BMD in Japanese men. Efforts aimed at the earlier detection of $\mathrm{AL}$ and identification of reduced BMD may be integral for the reduction of the burden of COPD on the society.

\section{Acknowledgments}

We thank the technicians at the Japanese Red Cross Kumamoto Health Care Center for their excellent technical assistance. We would like to thank Editage for English language editing.

\section{Author contributions}

Watanabe K, Onoue A, Kubota K, Higashi N, Hayashi T, Tsuda $\mathrm{T}$ and Omori $\mathrm{H}$ designed this research. Watanabe $\mathrm{K}$, Onoue A, Kubota $\mathrm{K}$ and Omori $\mathrm{H}$ contributed to the data collection. All authors contributed to data analysis, drafting or revising the article, gave final approval of the version to be published, and agree to be accountable for all aspect of the work.

\section{Disclosure}

The authors report no conflicts of interest in this work.

\section{References}

1. Global Initiative for Chronic Obstructive Lung Disease. Global strategy for the diagnosis, management, and prevention of chronic obstructive pulmonary disease; 2018.Available from: http://www.gold copd.com/. Accessed July 9, 2018.

2. Vestbo J, Hurd SS, Agustí AG, et al. Global strategy for the diagnosis, management, and prevention of chronic obstructive pulmonary disease: GOLD executive summary. Am J Respir Crit Care Med. 2013;187(4):347-365. doi:10.1164/rccm.201204-0596PP

3. Available from: http://www.who.int/news-room/fact-sheets/detail/ chronic-obstructive-pulmonary-disease-(copd). Accessed August 2, 2018

4. Available from: http://www.who.int/en/news-room/fact-sheets/detail/ the-top-10-causes-of-death. Accessed August 2, 2018.

5. Japanese Respiratory Society. The JRS Guidelines for the Management of Chronic Obstructive Pulmonary Disease. 5th ed. Tokyo: Medical Review Co., Ltd; 2018.

6. Mannino DM, Thorn D, Swensen A, Holguin F. Prevalence and outcomes of diabetes, hypertension and cardiovascular disease in COPD. Eur Respir J. 2008;32(4):962-969. doi:10.1183/09031936.00012408

7. Decramer M, Rennard S, Troosters T, et al. COPD as a lung disease with systemic consequences-clinical impact, mechanisms, and potential for early intervention. COPD. 2008;5(4):235-256. doi:10.1080/ 15412550802237531

8. Divo M, Cote C, de Torres JP, BODE Collaborative Group, et al. Comorbidities and risk of mortality in patients with chronic obstructive pulmonary disease. Am J Respir Crit Care Med. 2012;186 (2):155-161. doi:10.1164/rccm.201201-0034OC.

9. Gershon AS, Mecredy GC, Guan J, Victor JC, Goldstein R, To T. Quantifying comorbidity in individuals with COPD: a population study. Eur Respir J. 2015;45(1):51-59. doi:10.1183/09031936.00 061414

10. Sin DD, Anthonisen NR, Soriano JB, Agusti AG. Mortality in COPD: role of comorbidities. Eur Respir J. 2006;28(6):1245-1257. doi:10.1183/09031936.00133805 
11. Rabe KF, Watz H. Chronic obstructive pulmonary disease. Lancet. 2017;389(10082):1931-1940. doi:10.1016/S0140-6736(17)31222-9

12. Fabbri LM, Luppi F, Beghé B, Rabe KF. Complex chronic comorbidities of COPD. Eur Respir J. 2008;31(1):204-212. doi:10.1183/ 09031936.00114307

13. Lehouck A, Boonen S, Decramer M, Janssens W. COPD, bone metabolism, and osteoporosis. Chest. 2011;139(3):648-657. doi:10.1378/chest.10-1427

14. Sarkar M, Bhardwaj R, Madabhavi I, Khatana J. Osteoporosis in chronic obstructive pulmonary disease. Clin Med Insights Circ Respir Pulm Med. 2015;12(9):5-21.

15. Jørgensen NR, Schwarz P, Holme I, Henriksen BM, Petersen LJ, Backer V. The prevalence of osteoporosis in patients with chronic obstructive pulmonary disease - a cross sectional study. Respir Med. 2007;101(1):177-185. doi:10.1016/j.rmed.2006.03.029

16. Majumdar SR, Villa-Roel C, Lyons KJ, Rowe BH. Prevalence and predictors of vertebral fracture in patients with chronic obstructive pulmonary disease. Respir Med. 2010;104(2):260-266. doi:10.1016/j. rmed.2009.09.013

17. Duckers JM, Evans BA, Fraser WD, Stone MD, Bolton CE, Shale DJ. Low bone mineral density in men with chronic obstructive pulmonary disease. Respir Res. 2011;3(12):101. doi:10.1186/14659921-12-101

18. Graat-Verboom L, van den Borne BE, Smeenk FW, Spruit MA, Wouters EF. Osteoporosis in COPD outpatients based on bone mineral density and vertebral fractures. J Bone Miner Res. 2011;26 (3):561-568. doi:10.1002/jbmr.257

19. Nuti R, Siviero P, Maggi S, et al. Vertebral fractures in patients with chronic obstructive pulmonary disease: the EOLO Study. Osteoporos Int. 2009;20(6):989-998. doi:10.1007/s00198-008-0770-4

20. Sakurai-Iesato Y, Kawata N, Tada Y, et al. The relationship of bone mineral density in men with chronic obstructive pulmonary disease classified according to the Global Initiative for Chronic Obstructive Lung Disease (GOLD) Combined Chronic Obstructive Pulmonary Disease (COPD) assessment system. Intern Med. 2017;56 (14):1781-1790. doi:10.2169/internalmedicine.56.6910

21. de Luise C, Brimacombe M, Pedersen L, Sørensen HT. Chronic obstructive pulmonary disease and mortality following hip fracture: a population-based cohort study. Eur J Epidemiol. 2008;23(2):115122. doi:10.1007/s10654-007-9211-5

22. Lewis B, Tricia M, Jessica N, et al. Outcomes post hip fracture for patients with COPD. Eur Respir J. 2018;52(Suppl. 62):PA4145. doi:10.1183/13993003.01675-2018

23. Moayyeri A, Bingham SA, Luben RN, Wareham NJ, Khaw K-T. Respiratory function as a marker of bone health and fracture risk in an older population. J Bone Miner Res. 2009;24(5):956-963. doi:10.1359/jbmr.081231

24. Vrieze A, de Greef MH, Wijkstra PJ, Wempe JB. Low bone mineral density in COPD patients related to worse lung function, low weight and decreased fat-free mass. Osteoporos Int. 2007;18(9):1197-1202. doi:10.1007/s00198-007-0355-7

25. Watanabe R, Tanaka T, Aita K. et al. Osteoporosis is highly prevalent in Japanese males with chronic obstructive pulmonary disease and is associated with deteriorated pulmonary function. $J$ Bone Miner Metab. 2015;33(4):392-400. doi:10.1007/s00774-014-0605-7

26. Omori H, Nagano M, Funakoshi Y. et al. Twelve-year cumulative incidence of airflow obstruction among Japanese males. Intern Med. 2011;50(15):1537-1544. doi:10.2169/internalmedicine.50.4412

27. Oda M, Omori H, Onoue A. et al. Association between airflow limitation severity and arterial stiffness as determined by the brachial-ankle pulse wave velocity: a cross-sectional study. Intern Med. 2015;54(20):2569-2575. doi:10.2169/internalmedicine.54.3778

28. Onoue A, Omori H, Katoh T, et al. Relationship of airflow limitation severity with work productivity reduction and sick leave in a Japanese working population. Int J Chron Obstruct Pulmon Dis. 2016;11:567-575. doi:10.2147/COPD.S99786
29. Omori H, Tsuji M, Sata K, et al. Correlation of C-reactive protein with disease severity in CT diagnosed emphysema. Respirology. 2009;14(4):551-558. doi:10.1111/j.1440-1843.2009.01519.x

30. Masuda S, Omori H, Onoue A, et al. Comorbidities according to airflow limitation severity: data from comprehensive health examination in Japan. Environ Health and Prev Med. 2017;22(1):13. doi:10.1186/s12199-017-0620-0

31. Omori H, Kaise T, Suzuki T, et al. Prevalence of airflow limitation in subjects undergoing comprehensive health examination in Japan: survey of chronic obstructive pulmonary disease patients epidemiology in Japan. Int J Chron Obstruct Pulmon Dis. 2016;11:873-880. doi:10.2147/COPD.S99935

32. Miller MR, Hankinson J, Brusasco V, et al. Standardisation of spirometry. Eur Respir J. 2005;26(2):319-338. doi:10.1183/09031936. 05.00034805

33. Japanese Respiratory Society. Reference values for spirometry in Japanese adult [Internet]. Available from: http://www.jrs.or.jp/mod ules/guidelines/index.php?content_id=12. Accessed August 2, 2018.

34. WHO Scientific Group on the Prevention and Management of Osteoporosis. Prevention and Management of Osteoporosis: report of a WHO scientific group. WHO technical report series; 920 . Geneva: World Health Organization; 2003.

35. Sin DD, Man JP, Man SF. The risk of osteoporosis in Caucasian men and women with obstructive airways disease. Am J Med. 2003;114 (1):10-14. doi:10.1016/s0002-9343(02)01297-4

36. Herland T, Apalset EM, Eide GE, Tell GS, Lehmann S. Airflow limitation as a risk factor for low bone mineral density and hip fracture. Eur Clin Respir J. 2016;3:32214. eCollection 2016. doi:10.3402/ecrj.v3.32214

37. Miyamoto RG, Kaplan KM, Levine BR, Egol KA, Zuckerman JD. Surgical management of hip fractures: an evidence-based review of the literature. I: femoral neck fractures. J Am Acad Orthop Surg. 2008;16(10):596-607.

38. Farahmand BY, Michaëlsson K, Ahlbom A, Ljunghall S, Baron JA. Survival after hip fracture. Osteoporos Int. 2005;16(12):1583-1590. doi:10.1007/s00198-005-2024-z

39. Johnell O, Kanis JA, Odén A, et al. Mortality after osteoporotic fractures. Osteoporos Int. 2004;15(1):38-42. doi:10.1007/s00198003-1490-4

40. Kjensli A, Mowinckel P, Ryg MS, Falch JA. Low bone mineral density is related to severity of chronic obstructive pulmonary disease. Bone. 2007;40(2):493-497. doi:10.1016/j.bone.2006.09.005

41. Dennison EM, Dhanwal DK, Shaheen SO, et al. Is lung function associated with bone mineral density? Results from the Hertfordshire Cohort Study. Arch Osteoporos. 2013;8:115. doi:10.1007/s11657012-0115-y

42. Jaramillo JD, Wilson C, Stinson DS, et al. Reduced bone density and vertebral fractures in smokers. Men and COPD patients at increased risk. Ann Am Thorac Soc. 2015;12(5):648-656. doi:10.1513/ AnnalsATS.201412-5910C

43. de Pablo P, Cooper MS, Buckley CD, et al. Association between bone mineral density and C-reactive protein in a large population-based sample. Arthritis Rheum. 2012;64(8):2624-2631. doi:10.1002/art.34474

44. Samaria JK, Bhatia M. Raised CRP levels associated with osteoporosis in patients with COPD. Am J Respir Crit Care Med. 2015;191:5716.

45. Janssens W, Bouillon R, Claes B, et al. Vitamin D deficiency is highly prevalent in COPD and correlates with variants in the vitamin D-binding gene. Thorax. 2010;65(3):215-220. doi:10.1136/thx.2009.120659

46. Førli L, Halse J, Haug E, et al. Vitamin D deficiency, bone mineral density and weight in patients with advanced pulmonary disease. $J$ Intern Med. 2004;256(1):56-62. doi:10.1111/j.1365-2796.2004.01 337.x

47. Romme EA, Rutten EP, Smeenk FW, et al. Vitamin D status is associated with bone mineral density and functional exercise capacity in patients with chronic obstructive pulmonary disease. Ann Med. 2013;45(1):91-96. doi:10.3109/07853890.2012.671536 


\section{Publish your work in this journal}

The International Journal of COPD is an international, peer-reviewed journal of therapeutics and pharmacology focusing on concise rapid reporting of clinical studies and reviews in COPD. Special focus is given to the pathophysiological processes underlying the disease, intervention programs, patient focused education, and self management

protocols. This journal is indexed on PubMed Central, MedLine and CAS. The manuscript management system is completely online and includes a very quick and fair peer-review system, which is all easy to use. Visit http://www.dovepress.com/testimonials.php to read real quotes from published authors.

Submit your manuscript here: https://www.dovepress.com/international-journal-of-chronic-obstructive-pulmonary-disease-journal 